\title{
Nasal Prominence
}

National Cancer Institute

\section{Source}

National Cancer Institute. Nasal Prominence. NCI Thesaurus. Code C34217.

Lateral and medial horseshoe-shaped mesenchymal elevations surrounding the

embryonic nasal placodes that arise from a division of the frontonasal prominence and contribute to the formation of the nose. 